\title{
TuRISMO CULTURAL MÓVEL. ESPAÇOS, TEMPOS E LOGOS DA ARTE
}

\author{
Pedro de Andrade
}

\begin{abstract}
RESUMO
Os paradigmas globais e a escalabilidade dos processos de mobilidade mudaram profundamente no século passado (Adey, 2014). Um desses fenómenos móveis é o turismo, que constitui a configuração central da viagem dentro da modernidade (Andrade, 1993). As viagens modernas não constituem apenas um espaço e tempo de lazer pacífico, mas também uma arena conflituosa que subjaz e traduz outras questões sociais colaterais (Cohen, 2013; Rickly, 2016; Verstraete, 2009). Este texto apresenta um resumo de uma análise sociológica, referente a algumas questões levantadas no projeto Comunicação Pública da Arte, coordenado pelo autor e financiado pela Fundação para Ciência e Tecnologia-FCT (Ref. PTDC/CCI/68595/2006). No seio deste projeto, um questionário de pesquisa foi respondido por turistas que visitaram a exposição acima mencionada, numa amostra de 504 visitantes. O perfil "turista" incluiu 50 visitantes, e foi considerado pertinente para este estudo, na medida em que o Museu Berardo encontra-se situado numa área turística relevante de Lisboa, a freguesia de Santa Maria de Belém.
\end{abstract}

\section{PALAVRAS-ChAVE}

Mobilidades sociais; novas metodologias; turismo cultural; turista crítico/contra-turista; turismo popular

\section{Mobile CUltural tourism. Art spaces, times ANd logos}

\begin{abstract}
The global paradigms and the scalability of mobility processes changed deeply in the last century (Adey, 2014). One of such mobile phenomena is tourism, that constitutes the core configuration of the voyage within modernity (Andrade, 1993). Modern travels constitute not just a space and time of pacific leisure, but as well as a conflictual arena that underlies and translate other collateral social issues (Cohen, 2013; Rickly, 2016; Verstraete, 2009). This text presents a summary of a sociological analysis, regarding some questions raised within the project Public Communication of Art, coordinated by the author, and funded by Foundation for Science and Technology-FCT (Ref. PTDC/CCI/68595/2006). Within this project, a survey questionnaire was answered by tourists who visited the above-mentioned exhibition, inside a sample of 504 visitors. The tourist profile had 50 visitors, and it was considered pertinent for this study, as Museu Berardo is situated inside a relevant Lisbon touristic area, the parish of Santa Maria de Belém.
\end{abstract}

\section{KEYWORDS}

Critical tourist/counter tourist; cultural tourism; new methodologies; popular tourism; social mobilities 


\section{INTRODUÇÃO: MOBILIDADES TURÍSTICAS}

Os paradigmas globais e a escalabilidade dos processos de mobilidade mudaram profundamente no último século (Adey, 2014). Um desses fenómenos móveis é o turismo, que representa a configuração central da viagem dentro da modernidade (Andrade, 1993). A viagem moderna não constitui apenas um espaço e um tempo de lazer pacíficos, mas igualmente uma arena conflituosa que indicia e traduz outras questões sociais colaterais (Cohen, 2013; Rickly, 2016; Verstraete, 2009).

De um lado, o turista que parte de um país central na Europa ou dos Estados Unidos, muitas vezes transforma-se num turista crítico, ou seja, um viajante que tenta compreender a alteridade inerente às culturas visitadas, e por vezes antagoniza a sociedade de saída e os seus discursos sobre a viagem (Andrade, 1993). Um exemplo desta estratégia é o turismo lento, uma configuração de viagem onde o calendário industrial e as temporalidades dos horários são substituídos por um ritmo mais lento e às vezes introspetivo (Fullagar, 2012).

De outro lado, um tal turista central enfrenta amiúde um contra-turista, sendo este um membro da sociedade visitada que coloca em questão o comportamento e até mesmo a legitimidade dos visitantes (Andrade, 1993). Um caso de contra-turismo é o turismo popular, profundamente ligado a imaginários marginais, como as excursões periódicas e jantares coletivos promovidos pelos Grupos Excursionistas e Jantaristas. Estes grupos entendem-se como associações de trabalhadores cuja sede se situa dentro de tabernas e cafés em bairros populares de Lisboa. Essas viagens encontram-se profundamente conetadas com as culturas urbanas de vizinhança e com uma forma original de estética, a Arte Excursionista (Andrade, 1986).

Atualmente, o turismo revela-se uma indústria essencial no seio das sociedades contemporâneas e contribui profundamente para o intercâmbio intercultural global (Andrade, 2014; Barker, 2014). De fato, o turismo impulsiona tanto configurações ubíquas quanto locais das mobilidades urbanas, no que diz respeito à troca de capitais, trabalhadores, turistas, imigrantes, coisas, identidades e culturas (Burns, 2008; Cresswell, 2012). Em particular, a problemática e o estudo do turismo do património cultural (Hanna, 2015; Kaminski, 2014), requerem, simultaneamente, métodos clássicos, técnicas criativas (Goodson, 2004; Rakic, 2012) e métodos móveis (Scheller \& Isaacson, 2013; Scheller \& Urry, 2016). Esta perspetiva, entre outras, procura desconstruir os Estudos de Turismo clássicos, e reconstruir um campo social e semântico sobre as mobilidades urbanas (Andrade, 2017; Elliott \& Urry, 2010; Salazar \& Jayaram, 2016).

Nos atuais Estudos de Museus, um debate crescente diz respeito aos modos como os públicos lidam com esse espaço cultural. Alguns estudos sobre a experiência do visitante do museu são clássicos, por ex. os trabalhos de Eilean Hooper-Greenhill (1994) e John Falk (2009). É relevante descobrir como as audiências do museu constroem significados e melhoram a sua educação cultural (Falk, 2012). Assim sendo, os museus atraem cada vez mais a atenção dos públicos tendo em vista projetar exposições para melhorar as suas experiências e a sua "carreira de visitante" (Roppola, 2014). Alguns curadores de museus acreditam que certos segmentos de audiências já contribuíram para mudar 
a forma como a arte é apresentada publicamente (McLean, 2011). Em suma, as exposições tendem a ser centradas no visitante, e o curador deve entender a sua prática cultural como uma "edu-curadoria" (Villeneuve, 2017), vocacionada para o melhoramento da literacia cultural. Além das exposições, o próprio museu está a tornar-se num "museu centrado no visitante" (Samis, 2017).

Quanto ao perfil dos turistas no interior dos visitantes do museu, o património cultural é hoje profundamente promovido por um marketing agressivo (McCormick, 2014). Em particular, o turismo cultural tem sido objeto de políticas de revitalização e crescimento sustentáveis (Hargrove, 2017; Kirshenblatt-Gimblett, 1998). Uma consequência desta estratégia é a seguinte: o turismo cultural mudou a própria noção e natureza do museu (Kotut, 2011). No entanto, ao mesmo tempo, o património mundial precisa de proteção, conservação e atenção ao aumento do número de turistas (Bourdeau, 2018). Algumas práticas turísticas aumentaram exponencialmente nos últimos anos, como a fotografia turística realizada com dispositivos digitais (Stylianou-Lambert, 2016). Entretanto, o turismo cultural deve estar associado a um turismo mais cívico, relacionado com as diferentes culturas urbanas visitadas (Shilling, 2007). Uma tal cidadania praticada por turistas envolve a consciência de traumas coletivos, que pode ser desenvolvida no interior da viagem, como as paisagens de memória do 11 de Setembro de 2001 (Sather-Wagstaff, 2016).

\section{MOBILIDADES CULTURAIS TURÍSTICAS NO ESPAÇO, TEMPO E LOGOS DA ARTE DO MUSEU}

Em tais conjunturas sociais e sociológicas, é essencial saber ler e escrever a genealogia do passado e do presente, relativa às atividades turísticas. Este texto irá apresentar apenas uma parte desse percurso, um exemplo de estudo empírico sobre a mobilidade dos visitantes de museus, incluindo turistas circulantes numa exposição intitulada 'Sem Rede' que mostrou obras criadas pela artista Joana Vasconcelos e que teve lugar no Museu Coleção Berardo, em Lisboa, 2010'.

Discutiremos em seguida a síntese de uma análise sociológica, sobre algumas questões levantadas no âmbito do projeto Comunicação Pública de Arte, coordenado pelo autor, e financiado pela Fundação para a Ciência e Tecnologia-FCT².

\footnotetext{
' Como mencionado acima, os trabalhos referidos no artigo estão inseridos nas seguintes dimensões da problemática: dois estudos teóricos e empíricos incidem sobre os museus de ciência e arte e seus públicos, e foram realizados a partir de projetos financiados pela Fundação para a Ciência e Tecnologia-FCT, pelo autor e pela equipa destes projetos. Além disso, uma reflexão epistemológica, teórica e metodológica, denominada Sociologia Semântico-Lógica, baseou-se em estudos de caso na era das redes digitais. Outros ensaios do autor enfocam o turismo popular, em particular o turismo excursionista empreendido por trabalhadores, e o turismo como a forma dominante da viagem dentro da modernidade. Ainda outras pesquisas teóricas e de terreno falam sobre as seguintes dimensões dos museus e do turismo cultural: em primeiro lugar, os públicos de museus, uma vez que constituem a parte empírica deste artigo. Mas também alguns trabalhos contextualizam possíveis estudos futuros sobre interculturalismo, mobilidades urbanas, migrações, a metodologia da Sociologia Cultural do Património Cultural, bem como acerca das novas tecnologias digitais.
}

${ }^{2}$ Ref. PTDC/CCI/68595/2006. 
TEMA

O artigo foca a problemática do turismo cultural em um quadro contextual geral e um caso particular. O quadro contextual é o processo social de mobilidade urbana. E o caso particular aqui é a visita ao museu de arte por parte de um público de turistas. Por outras palavras, o tema central e sua problemática não podem ser reduzidos a processos de turismo cultural. Nem este tema é limitado ao público de museus (turistas culturais, etc.), nem à metodologia de tal estudo. As duas últimas posturas empobreceriam o texto para uma perspetiva empirista e positivista. Em suma, aqui falamos principalmente da visita ao museu de arte pelo turista cultural, no contexto das mobilidades urbanas.

\section{Prolegómenos metodológicos}

Dentro deste projeto, um inquérito por questionário foi respondido pelos visitantes do museu que estiveram presentes na exposição acima mencionada, considerando uma amostra de 504 visitantes que incluiu vários segmentos (famílias, professores, estudantes, turistas). O perfil turístico contou com 50 visitantes, e foi considerado pertinente para este estudo, uma vez que o Museu Berardo está situado dentro de uma área turística relevante de Lisboa, a freguesia de Santa Maria de Belém³.

Uma parte da análise e da interpretação dos questionários do inquérito ao Museu Coleção Berardo será apresentada a seguir. Mostra-se, em primeiro lugar, uma análise multivariada geral e, em segundo lugar, várias análises estatísticas univariadas, com o objetivo de especificar algumas características particulares dos dados recolhidos. ${ }^{4}$

\section{CARACTERÍSTICAS DOS TURISTAS E SUAS PRÁTICAS}

O diagrama da Figura 1 mostra uma análise multivariada usando o teste de $X^{2}$, aplicável às variáveis nominais consideradas no questionário5.

\footnotetext{
${ }^{3}$ Esta divisão em sub-amostras permite a comparação dos respetivos segmentos de audiência. No entanto, isso não pode ser alcançado no espaço restrito deste artigo, que lida mais com a especificidade de um único perfil, embora também se refira aos demais elementos da amostra, estudados em outras fontes. Para mais detalhes sobre outros segmentos de visitantes de museus, veja: Andrade, 2016, pp. 163-199 e Andrade, 2010, pp. 150-280. Outro estudo relacionado com o turismo científico considera um segmento específico de turistas, constituídos por investigadores (Slocum \& Kline, 2015).

${ }^{4}$ Numa análise multivariada, algumas variáveis são frequentemente consideradas (embora nem sempre) como variáveis independentes, que condicionam as variáveis dependentes. De fato, as variáveis independentes frequentemente representam estruturas sociais incorporadas num ator social, enquanto as variáveis dependentes podem representar ações (por exemplo, as "compras no museu") ou opiniões (por exemplo, uma opinião sobre o conforto no espaço do museu). Exemplos de variáveis independentes: a variável "género", que não deve ser confundida com "sexo", um termo que muitas vezes é entendido como um indicador sociodemográfico empírico, mais adaptável a uma pergunta dentro de um questionário); "idade", que pode ser uma variável ou um indicador empírico, embora as variáveis "geração" ou "classe de idade" sejam mais utilizadas em estudos aprofundados. Ilustração de variáveis dependentes: "primeira visita ao museu".

${ }_{5} \mathrm{O}$ teste do $\mathrm{X}_{2}$ ou chi-quadrado constitui apenas uma das possíveis medidas para a análise multivariada. Aqui, este instrumento analítico foi considerado, por razões de espaço, somente no contexto de apresentação de uma análise geral das relações entre as variáveis consideradas. De fato, as combinações possíveis desse tipo de análise revelam-se muito numerosas, e outras análises multivariadas sobre os temas discutidos neste artigo podem ser encontradas no trabalho mencionado anteriormente (Andrade, 2016). Em vez disso, e para fins de síntese, aqui o autor forneceu uma breve explicação da análise multivariada, seguida de uma interpretação mais detalhada dos dados da análise univariada, para cada uma das variáveis selecionadas.
} 


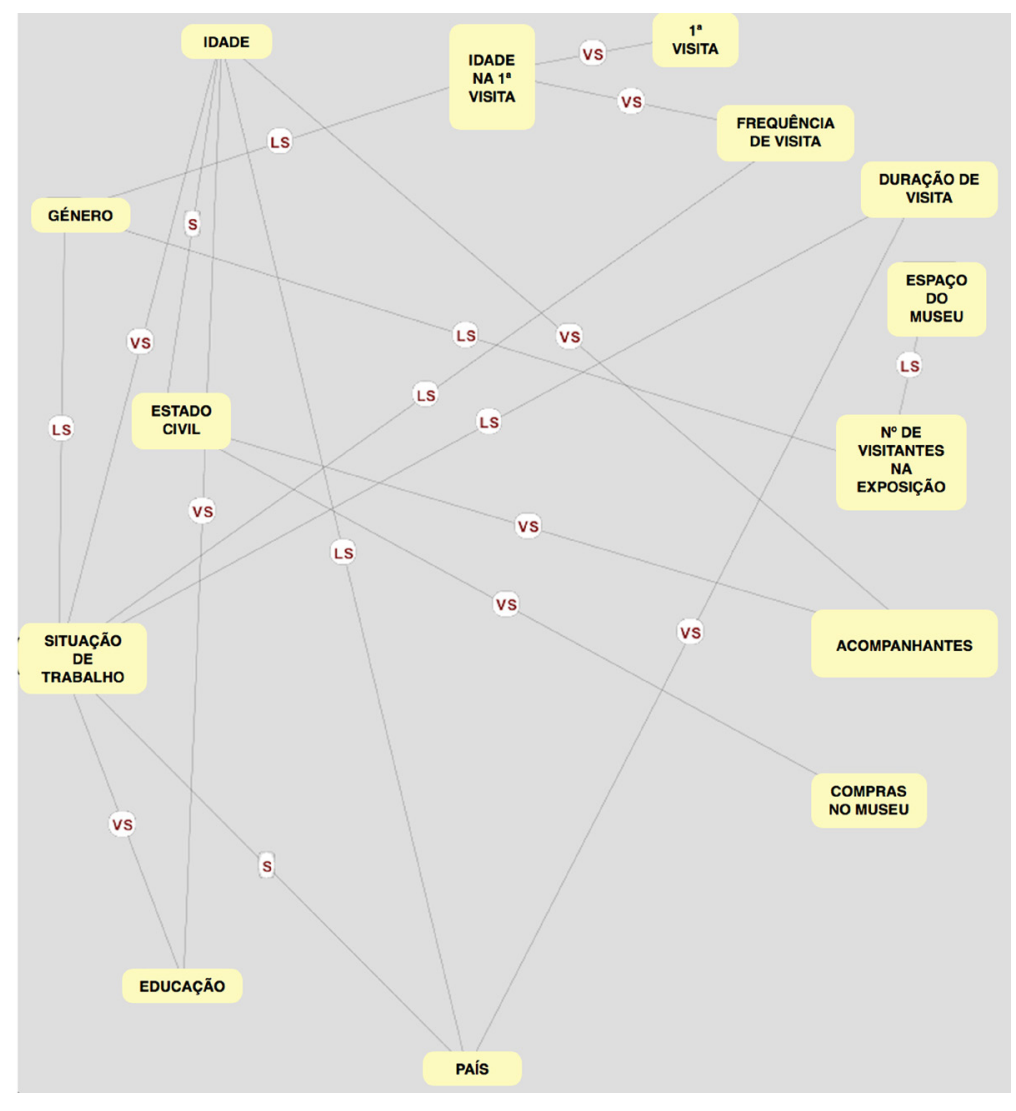

Figura 1: Turistas e visita ao museu

A imagem elucida as relações estabelecidas entre: por um lado, as características estruturais ou sociodemográficas dos turistas (idade, género, estado civil, situação de trabaIho, nível de escolaridade e país de residência); e, por outro lado, as ações desenvolvidas por eles durante a visita ao espaço e tempo do museu (primeira visita, frequência de visita e duração, compras no museu). Esta situação contextual é parcialmente definida pelo número de visitantes e pelos acompanhantes dos visitantes. Por outras palavras, tais práticas atestam os fluxos de arte subjacentes aos espaços (spaces) e paisagens (scapes) do museu.

Nesta imagem sintética, apenas as associações mais relevantes são visíveis: "S" quer dizer "significativo" e "VS" traduz-se por "muito significativo". As ligações "LS" conotam uma relação "menos significativa" e "NS" é uma abreviatura de "não significativo". Estas últimas relações foram descartadas do esquema, a fim de alcançar uma sua maior legibilidade. $\mathrm{Na}$ amostra considerada, a maioria das conexões parece ser muito significativa (9), sendo duas apenas significativas e seis emergem como menos significativas.

Também é possível analisar separadamente algumas das características específicas deste público de fluxos de arte, como cada uma das estruturas sociodemográficas (idade, género, etc.) incorporadas no turista. Neste plano, a categoria de relacionamentos "muito significativos" pontua 3, e encontramos dois elos significativos e duas conexões menos significativas entre essas variáveis. Isso indica, entre outros critérios, que a nossa amostra é bastante estável. 


\section{TURISTAS NO SEIO DOS ESPAÇOS, TEMPOS E DISCURSOS DO MUSEU}

Além disso, a análise univariada apresentada abaixo foi mais aprofundada através de uma interpretação sociológica incluindo articulações sociais entre o tempo e o espaço em que esses fluxos artísticos móveis ocorrem.

Considerando tais objetivos, desenvolvemos um método de ciências sociais inspirado no conceito deixis, forjado na filosofia grega. A noção de deixis pode ser definida como a conexão entre o tempo humano, o espaço humano e o logos. Este último termo significa a razão, a linguagem, a linguagem da razão e a razão da linguagem, subjacentes à ação de um sujeito em relação aos seus objetos de experiência e conhecimento do mundo que o rodeia. No nosso contexto, o "sujeito" é o ator social "turista", movendo-se dentro dos ritmos (temporalidades) e territórios (espacialidades) do museu de arte. Por exemplo. quando e onde o turista tenta experimentar e entender "objetos de arte" usando específicas linguagens sociais artísticas e de lazer. Nomeámos esta abordagem Metodologia GeoNeoLógica, na medida em que interpreta o espaço (donde o prefixo "geo"), o tempo e os seus processos de inovação ("neo") através de manifestações sociais do logos (Andrade, 2011) .

Começaremos a análise por algumas das temporalidades sociais dos fluxos de arte, por exemplo, o tempo biográfico do turista. Em primeiro lugar, é necessário saber quantos visitantes visitam o museu pela primeira vez. Isso constitui, no campo empírico, a nossa primeira variável sociológica para a análise univariada, representando dados coletados no terreno do museu.

\begin{tabular}{lc}
\hline \multicolumn{2}{c}{ Primeira Visita do TURISTA } \\
\hline Q ı. É a primeira vez que visita uma exposição sobre arte? \\
\hline Sim & $6,00 \%$ \\
\hline Não & $94,00 \%$ \\
\hline
\end{tabular}

Tabela 1: Metodologia GeoNeoLógica aplicada ao museu:o tempo biográfico turístico

\footnotetext{
${ }^{6}$ A bibliografia aqui reunida articula-se com o modelo epistemológico-teórico-empírico aqui exposto, fundado na deixis. Como se constatou, este termo originou-se na filosofia grega e significa a conexão tripartida entre espaço, tempo e sujeito social (um agente ou ator) que ativa e atualiza este espaço-tempo, através do seu logos (isto é, a sua linguagem, a sua razão, a linguagem da razão ou a razão da linguagem). E a estrutura e a validade do modelo apoiado nessas três dimensões sociais são verificadas na discussão dos dados do terreno, através de diversas variáveis empíricas cujas relações são apresentadas na análise multivariada da Figura 1. Quanto às variáveis sociológicas, Paul Lazarsfeld (1993, pp. 172-188) distingue vários passos para a sua construção, na sua metodologia de mensuração quantitativa da realidade social: a definição das dimensões sociais relevantes que caraterizam o objeto de estudo; as variáveis reconstruídas pelo cientista social para representar tais dimensões; os indicadores sociais, ou seja, as variáveis mais concretas e mensuráveis que permitem a coleta de dados no campo empírico; e os índices, que são agregações das variáveis elaboradas nas fases anteriores. Para mais detalhes, veja também os esclarecimentos de Hynek Jerábek sobre a metodologia de Lazarsfeld (2006). Nesta perspetiva, podemos notar o seguinte: primeiro, a dimensão do espaço social do museu é aqui exemplificada pela variável empírica ou indicador social "conforto no espaço do museu". Em segundo lugar, o tempo biográfico da carreira cultural dos turistas é medido pelas seguintes variáveis ou indicadores empíricos: "primeira visita"; "idade na primeira visita"; "duração da visita". Terceiro, o processo que envolve o ator social "turista" em interação com o espaço-tempo do museu e com outros visitantes é representado pelas variáveis empíricas restantes. Finalmente, deve-se reparar que, em qualquer estudo específico, e em particular na sua apresentação, é necessário selecionar as variáveis mais relevantes e representativas, por uma questão de clareza da explicação.
} 
A Tabela 1 representa as respostas à Questão 1 do questionário: "Esta é a sua primeira visita a uma exposição de arte?". Podemos notar que, de alguma forma, a esmagadora maioria dos visitantes (94\%) não se considera um debutante nesse tipo de evento cultural.

Tal resultado emerge relacionado à frequência do museu, prática testemunhada pelas respostas da questão 1.2: "Com que frequência visita exposições de arte?"

Em primeiro lugar, a visita mensal a um museu é a mais frequente, de acordo com $38 \%$ dos turistas inquiridos neste estudo (Figura 2). Em segundo lugar, 8\% dos visitantes vão a um museu trimestralmente e $10 \%$ uma vez por semana. Tanto as visitas anuais como as semestrais recebem $6 \%$ das "votações". As outras regularidades são menos significativas. Em suma, as idas de turistas a exposições de arte denotam um elevado grau de frequência, no caso do padrão temporal de visitas ao Museu Colecção Berardo.

Quanto à duração de cada visita, a seguinte informação foi pedida através da Pergunta 2.2.: "Aproximadamente quanto tempo durou a sua visita?". Conforme se observa no Gráfico 1, mais da metade (54\%) dos visitantes normalmente realiza uma viagem de uma hora. Este valor recebe mais do dobro das respostas que subscrevem a jornada artística realizada em menos de uma hora ou em duas horas ( $22 \%$ cada). A busca de arte levada a cabo em três horas revela-se uma escolha mais rara $(2 \%)$.

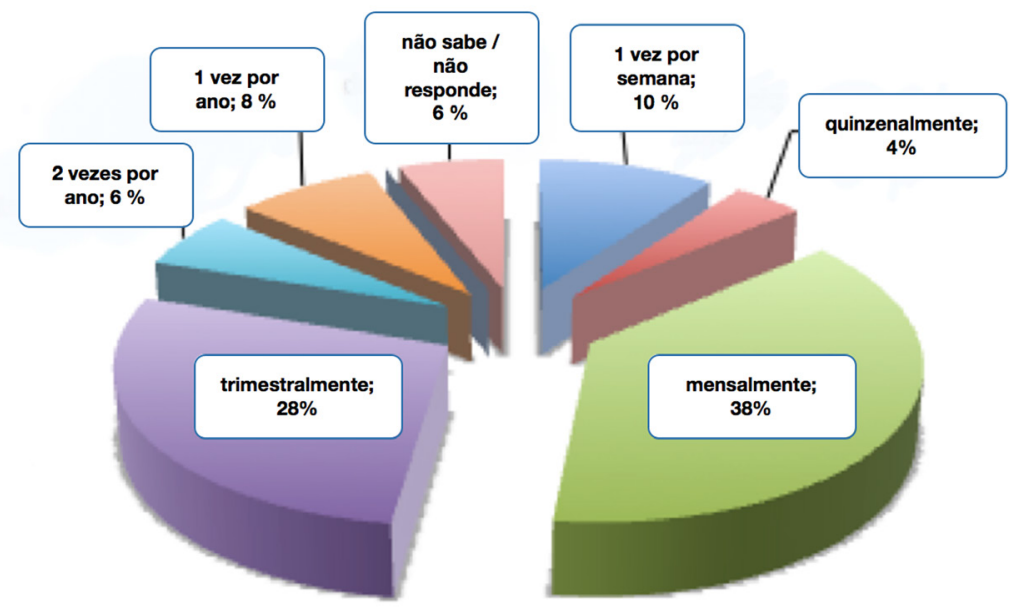

Gráfico 1: periodicidade da visita turística como uma manifestação de "tempo" uma das três dimensões da deixis

A segunda dimensão da metodologia GeoNeoLógica usando a deixis é o espaço social dos fluxos. A esse respeito, foi colocada uma questão aos turistas perguntando se algum aspeto do museu / exposição interna contribuiu, de forma positiva ou negativa, para a conveniência ou conforto físico de sua visita (Tabela 2). Cerca de dois terços responderam de forma positiva, expressando a sua satisfação com as condições gerais da organização em relação à dimensão espacial das mobilidades da arte. 


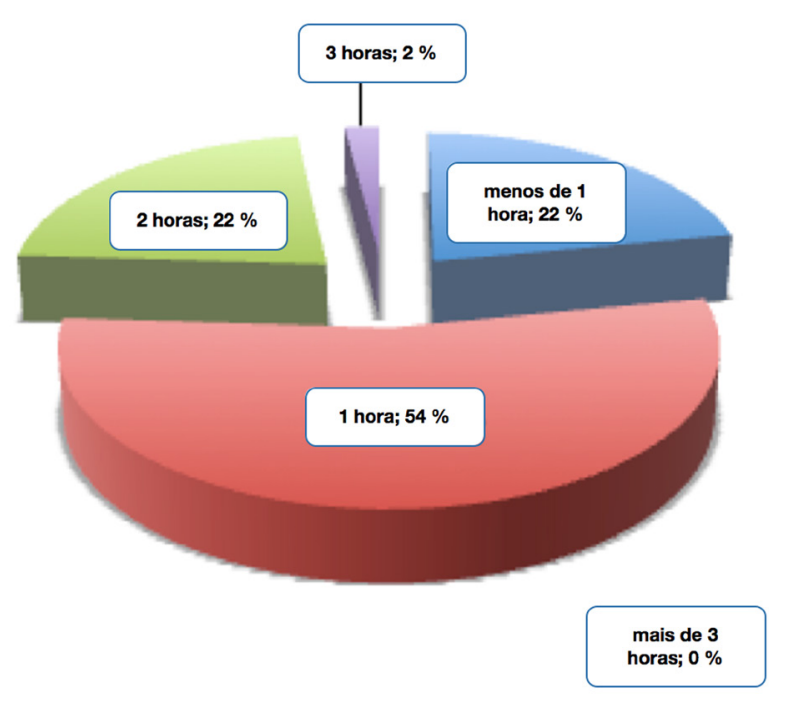

Gráfico 2: duração da visita turística como prática do tempo cultural

As atividades comerciais do museu são subsidiárias de seu território. Muitos dos visitantes não compraram nada no museu (Tabela 3), provavelmente por o considerarem um espaço mais estritamente cultural, entre outras possíveis razões.

\begin{tabular}{lc}
\hline \multicolumn{2}{c}{ Espaço do museu } \\
\hline $\begin{array}{l}\text { Q 4.3. Algum aspeto referente ao espaço interno do museu ou rela- } \\
\text { tivo à exposição contribuiu para o conforto físico de sua visita? }\end{array}$ \\
\hline Sim & $72,00 \%$ \\
\hline Não & $28,00 \%$ \\
\hline \multicolumn{3}{l}{ Tabela 2: Opinião turística no território do museu }
\end{tabular}

Finalmente, a terceira dimensão da deixis, isto é, o logos mobilizado pelo sujeito social (agente ou ator), pode ser observado empiricamente através da linguagem do turista, quando ele se refere a si mesmo e a outros visitantes, em estreito diálogo com o discurso veiculado pelo museu.

\begin{tabular}{lc}
\hline \multicolumn{2}{c}{ Compras do museu } \\
\hline Q 3.3 Fez algumas compras no museu (comprou alguma coisa na loja do museu)? \\
\hline $\operatorname{Sim}$ & $2,00 \%$ \\
\hline Não & $98,00 \%$ \\
\hline \multicolumn{2}{c}{ Tabela 3: Comércio ou cultura? }
\end{tabular}

Tais referências recíprocas desconstroem e reconstroem redes sociais públicas no museu, tecidas: (a) entre turistas; (b) entre eles e os diferentes sujeitos institucionais envolvidos ou em uma co-presença móvel, por exemplo, os profissionais do museu, 
curadores, artistas ou outros visitantes; (c) entre turistas e a dimensão anterior, os cenários e os territórios culturais do museu.

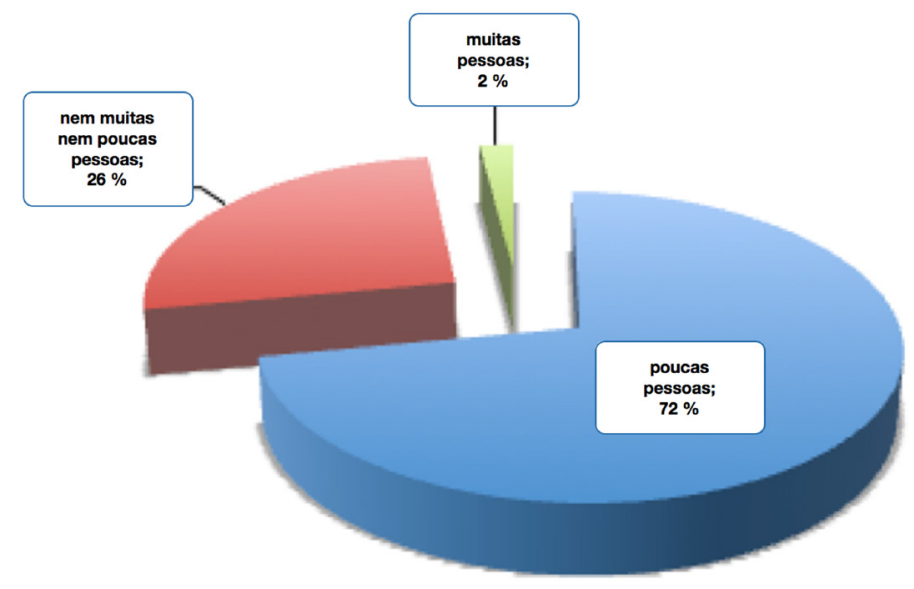

Gráfico 3: Redes sociais turísticas no museu: aspetos quantitativos

Quanto a esta relação entre o espaço de fluxos e o sujeito sociocultural, a questão 6.3. colocou a seguinte interrogação: "Com quantas pessoas circulando nas salas do museu, prefere ver a exposição: com poucas pessoas, com muitas pessoas ou outra quantidade de visitantes?". A análise mostrou que os turistas preferem uma menor ocupação das paisagens culturais, provavelmente para observar mais atentamente as obras de arte (ver Gráfico 3).

Além disso, quando confrontados com questões relativas a um acompanhante durante a visita, os turistas respondem que costumam ir com outras pessoas para visitar o museu (ver Tabela 4).

\begin{tabular}{ll}
\hline Acompanhantes do visitante & \\
\hline Q 6.1. Está a visitar esta exposição com alguém? & \\
\hline Sim & $96,00 \%$ \\
\hline Não & $4,00 \%$ \\
\hline
\end{tabular}

Tabela 4: redes sociais turísticas no museu: aspetos qualitativos

Outra questão que diz respeito à dimensão do sujeito sociocultural é a sua caraterização em termos das estruturas sociais incorporadas nas práticas dos agentes. Por outras palavras, todos os visitantes do museu estão incluídos numa dada classe de idade, num género, numa situação de trabalho ou noutras situações de pertença na sociedade global em que os atores sociais atualizam as suas vidas móveis no interior dos respetivos diálogos e ações diários.

Se começarmos por definir os turistas pelo local de residência no país de partida (Gráfico 4), a predominância de residentes em Espanha é notória, representando quase metade dos visitantes do museu de arte. Aqueles turistas oriundos de Itália vêm em 
seguida, com $14 \%$ do total, seguidos pelos habitantes na Bélgica (10\%) e na Alemanha (8\%). Os visitantes vindos da França, Inglaterra e Dinamarca registram assiduidades similares (4\%). Os turistas dos Estados Unidos da América, México, Polónia e Suíça contribuem apenas com um mínimo de casos, apenas $2 \%$.

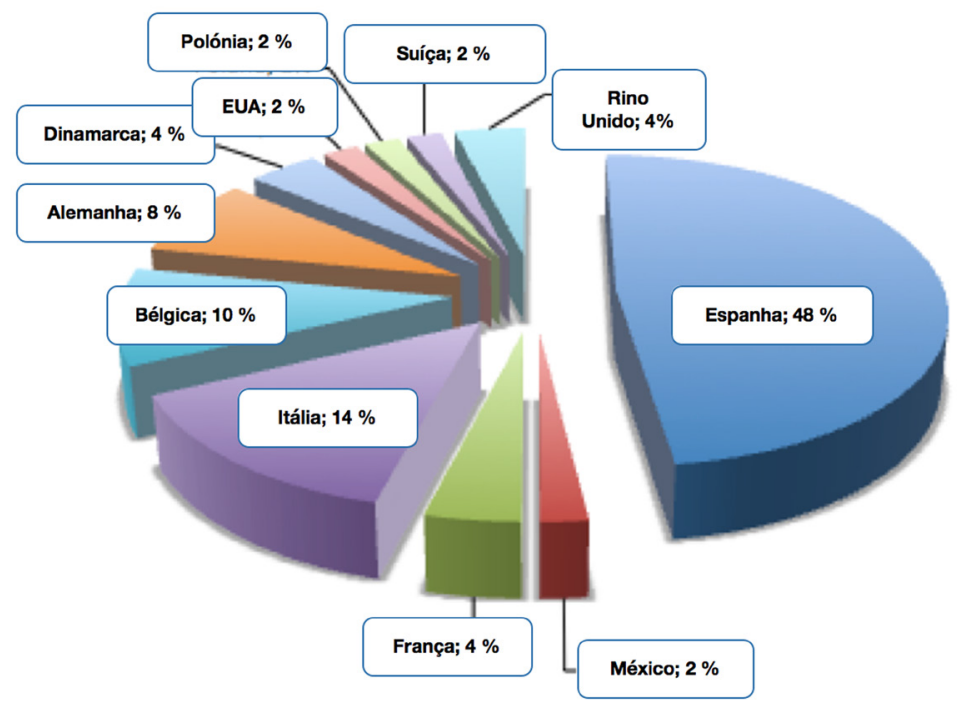

Gráfico 4: Local de residência dos turistas

Quanto ao fator idade (ver Gráfico 5), trata-se principalmente de um público jovem, com ênfase particular nas idades entre 20 e 29 anos (39\%) e 30 a 39 anos (33\%), que dobram a frequência da visita das outras classes de idade.

É interessante comparar a idade atual dos turistas com a idade de sua primeira visita a um museu (Gráfico 6). Estes eventos relacionam duas dimensões da deixis, o tempo e o agente social. Aqui. os jovens turistas também se destacam e até a sua percentagem (71\%) aumenta, indicando que a iniciação nas exposições de arte ocorre relativamente cedo na biografia e carreira do turista cultural.

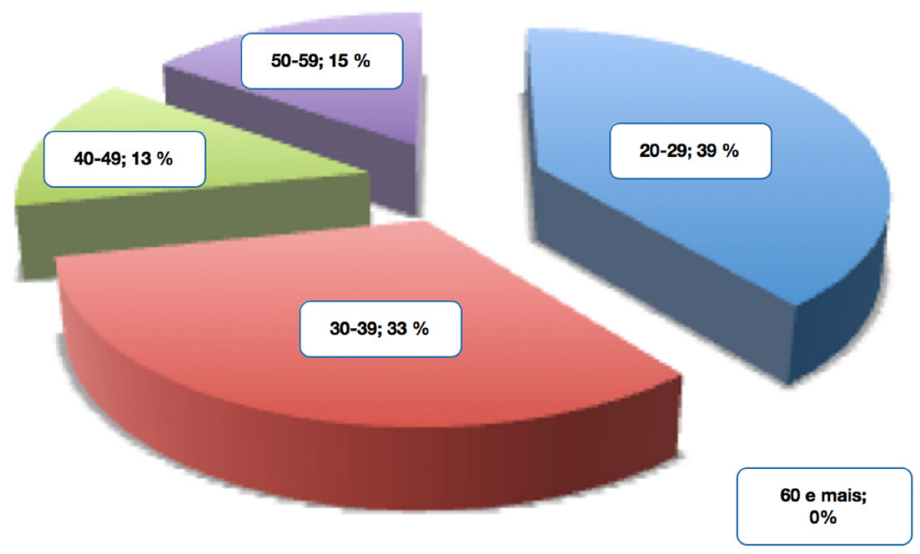

Gráfico 5: Idade como traço da carreira do turista cultural 


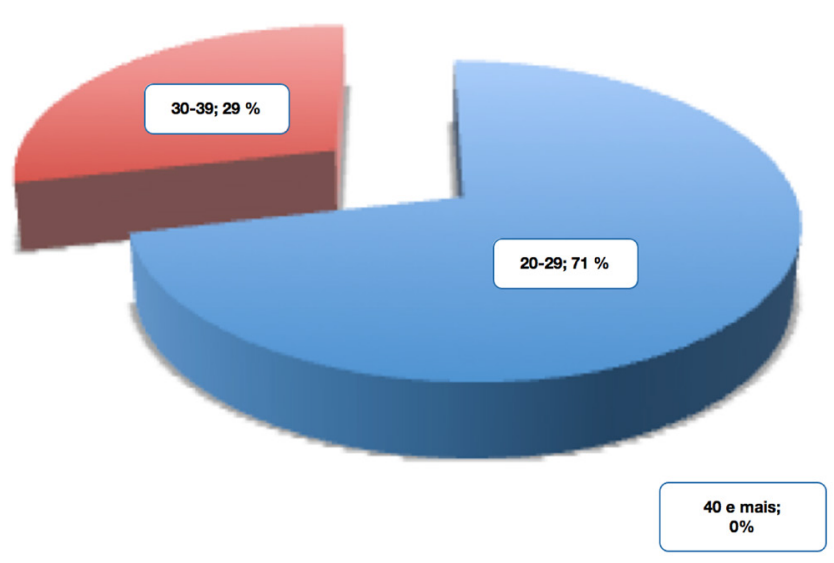

Gráfico 6: Primeira visita como parte da biografia cultural turística

Estranhamente ou não, uma mulher como a artista Joana Vasconcelos mobilizou uma audiência predominantemente feminina para a sua exposição (ver Tabela 5). Este fato ou feito, se associado a outros, pode esclarecer vários parâmetros de uma possível e provável tendência para uma feminização da cultura turística, tanto no que diz respeito à produção quanto à receção da arte.

\begin{tabular}{ll}
\hline & Género \\
\hline masculino & $36,00 \%$ \\
\hline feminino & $64,00 \%$ \\
\hline
\end{tabular}

Tabela 5: Feminização da cultura do turismo

No que toca o estado civil dos turistas (ver Gráfico 7), os solteiros vão mais frequentemente ao museu do que os casados ( $44 \%$ versus $26 \%$ ), pelo menos para a exposição "Sem Rede" aqui examinada. Outros estudos de audiência de museus, se comparados com este, podem esclarecer uma tal regularidade eventual.

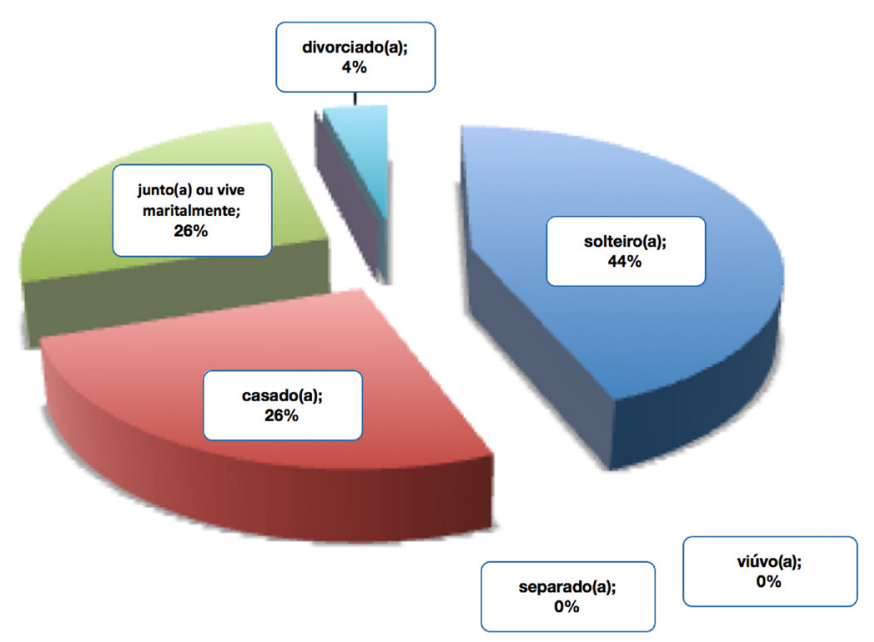

Gráfico 7: Cultura do turismo e a instituição familiar 
Quanto à situação de trabalho dos turistas (ver Gráfico 8), os trabalhadores / empregados / funcionários públicos prevalecem sobre os outros (50\%), mas as profissões liberais também se encontram bem representadas (30\%). Os proprietários e estudantes aparecem igualmente com algumas contribuições (8\%). Desempregados e reformados dos são raros.

O nível de educação turística tem influência na sua competência para entender as obras de arte exibidas, ou seja, a sua literacia artística. Um tal capital cultural dos entrevistados nesta pesquisa (Gráfico 9) é bastante alto, dois terços possuindo um diploma de ensino superior ( $84 \%$ ) e outros $6 \%$ de visitantes tendo frequentado um curso superior, embora sem o terminarem. De um modo sintético, cerca de $90 \%$ dos turistas tiveram contato direto, em termos de educação oficial, com conhecimento universitário e, provavelmente, com a "alta cultura".

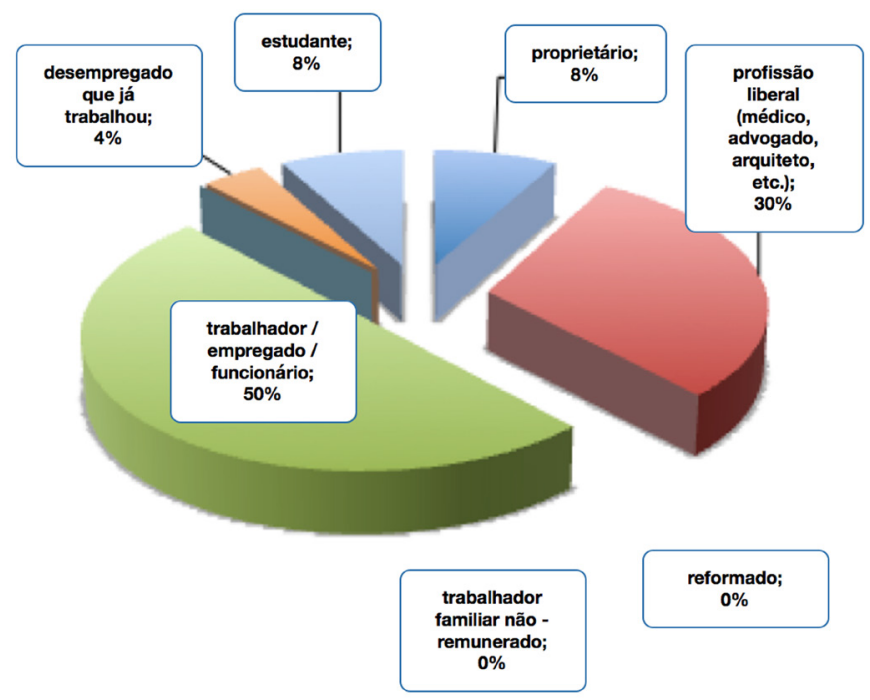

Gráfico 8: Visita de arte e situação de trabalho turístico

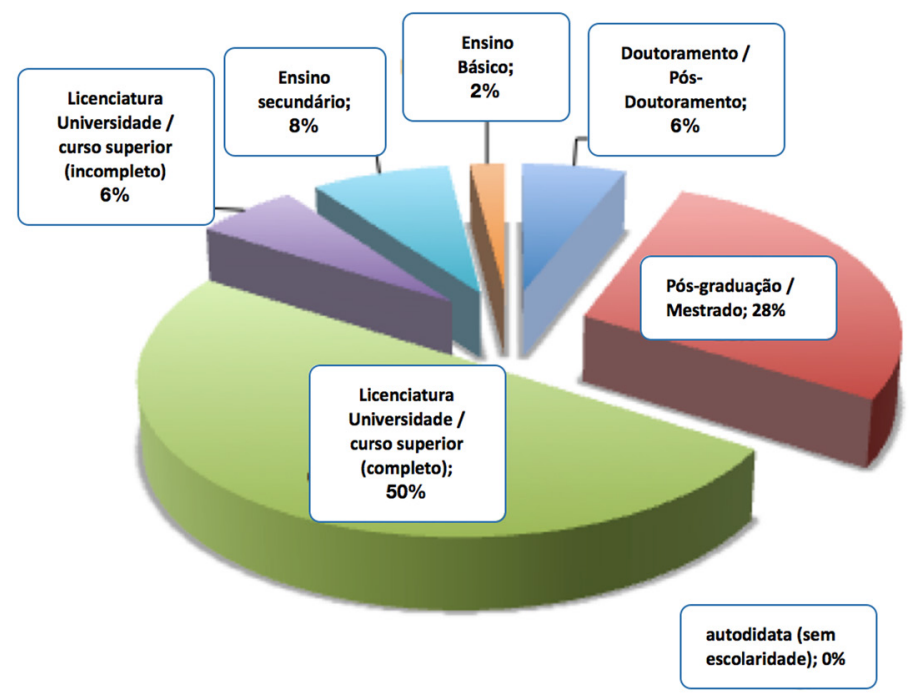

Gráfico 9: Educação turística e literacia artística 


\section{Conclusão}

Espaço, tempo e logos representam e apresentam apenas três das múltiplas dimensões do turismo cultural móvel. Este estudo apresentou uma metodologia fundamentada em três dimensões que constituem a deixis, aplicadas a algumas manifestações concretas dentro do museu de arte. No entanto, as espacialidades, temporalidades e incorporações sociais do turista cultural, proliferam dentro de nossa contemporaneidade, não apenas através dos fluxos artísticos, mas também no seio de outras esferas sociais. Por exemplo, no interior dos fluxos do ciberespaço e do cibertempo, onde e quando os sujeitos digitais se encontram a transformar irreversivelmente a nossa noção do logos, através da criação e partilha de novas formas de linguagens da razão e de inéditas razões da linguagem.

\section{REFERÊNCIAS}

Adey, P. et al. (Eds.) (2014). The Routledge handbook of mobilities. Routledge.

Andrade, P. (1986). A arte excursionista. Colóquio-Artes, 68, 5-11. [Web of Science reference number: A1986A930600001].

Andrade, P. (1993). Sociologia da viagem: deslocações diárias e anti-quotidiano nómada. Revista Crítica de Ciências Sociais, 37, 51-77.

Andrade, P. (Ed.) (2010). Museus, públicos e literacia científico-tecnológica: redes de comunicação de significados no espaço interdimensional do museu. Edições Colibri.

Andrade, P. (2011). Sociologia semântico-lógica da Web 2.0/3.0 na sociedade da investigação: significados e discursos quotidianos em blogs, wikis, mundos/museus virtuais e redes sociais semântico-lógicas. Edições Caleidoscópio.

Andrade, P. (2014). Post-colonial co-ordinary literature and Web 2.0/3.0: thinking back within transmediatic knowledge. In M. Pope (Ed.), New literary hybrids in the age of multimedia expression: crossing borders, crossing genres (pp. 17, 123-144). Amsterdão: John Benjamin Press.

Andrade, P. (Ed.) (2016). Comunicação pública da arte: o caso dos museus de arte locais e globais. Edições Caleidoscópio.

Andrade, P. (2017). Cultural e-tourism depicted by digital discourse: the case of Portuguese betworks of e-heritage and discursive innovation. In M. Bielenia-Grajewska \& M. Ríos (Eds.), Innovative Perspectives on Tourism Discourse (pp.1-17). Hershey: IGI Global.

Barker, A. (2014). Identity and intercultural exchange in travel and tourism. Bristol: Channel View Publications.

Bourdeau, L. (2018). World heritage, tourism and identity: inscription and co-production. Londres: Routledge.

Burns, P. \& Novelli, M. (Eds.) (2008). Tourism and mobilities: local-global connections. Wallingford: CABI.

Cohen, S. (2013). Lifestyle mobilities: intersections of travel, leisure and migration. Farnham: Ashgate Publishing Company.

Cresswell P. \& Merriman, T. (2012). Geographies of mobilities: Practices, spaces, subjects. Farnham: Ashgate Publishing Company. 
Elliott, A. \& Urry, J. (2010). Mobile lives. Londres: Routledge.

Falk, J. (2009). Identity and the museum visitor experience. Walnut Creek, CA: Left Coast Press.

Falk, J. (2012). Learning from museums: visitor experiences and the making of meaning. Lanham: AltaMira Press.

Fullagar, S., Markwel, K. \& Wilson, E. (Eds.) (2012). Slow travel and tourism: experiences and mobilities. Bristol: Channel View Publications.

Goodson, L. (Ed.) (2004). Qualitative research in tourism: ontologies, epistemologies and methodologies. Londres: Routledge.

Hanna, S. et al (Eds.) (2015). Social memory and heritage tourism methodologies. Londres: Routledge.

Hargrove, C. (2017). Cultural heritage tourism: 5 steps for revitalization and sustainable growth. Lanham, Maryland: Rowman \& Littlefield.

Hooper-Greenhill, E. (1994). Museums and their visitors. Londres: Routledge.

Kaminski, J., Benson, A. \& Arnold, A. (Eds.) (2014). Contemporary issues in cultural heritage tourism. Londres: Routledge.

Kirshenblatt-Gimblett, B. (1998). Destination culture: tourism, museums, and heritage. Berkeley: University of California Press.

Kotut, E. (2011). Cultural tourism and the museum concept. Saarbrücken: LAP Lambert Academic Publishing. Jerábek, H. (2006). Paul Lazarsfeld's research methodology. Prageu: Karolinum Press, Charles University.

Lazarsfeld, P. (1993). On social research and its language. Chicago: University of Chicago Press.

McCormick, R. (2014). Marketing cultural and heritage tourism: a world of opportunity. Londres: Routledge.

McLean, B. (2011). How visitors changed our museum: transforming the Gallery of California Art at the Oakland Museum of California. California: Oakland Museum of California.

Rakic, T. \& Chambers, D. (2012). An introduction to visual research methods in tourism. Londres: Routledge.

Rickly, J., Hannam, K. \& Mostafanezhad, M. (Eds.) (2016). Tourism and leisure mobilities: politics, work, and play. Londres: Routledge.

Roppola, T. (2014). Designing for the museum visitor experience. Londres: Routledge.

Salazar, N. \& Jayaram, K. (Eds.) (2016). Keywords of mobility: critical engagements. Nova lorque: Berghahn Books.

Samis, P. (2017). Creating the visitor-centered museum. Londres: Routledge.

Sather-Wagstaff, J. (2016). Heritage that hurts: tourists in the memory scapes of September 11. Londres: Routledge.

Sheller, M. \& Urry, J. (2006). Mobile technologies of the city. Londres: Routledge.

Sheller, N. \& Isaacson, M. (2013). Tourist mobility and advanced tracking technologies. Londres: Routledge.

Shilling, D. (2007). Civic tourism: the poetry and politics of place. Prescot, Arizona:Sharlot Hall Museum Press 
Slocum, S. \& Kline, C. (Eds.) (2015). Scientific tourism: researchers as travellers. Londres: Routledge.

Stylianou-Lambert, T. (2016). Museums and visitor photography: redefining the visitor experience. Boston: MuseumsEtc

Verstraete, G. (2009). Tracking Europe: mobility, diaspora, and the politics of location. Durham, North Carolina: Duke University Press.

Villeneuve, P. (2017). Visitor-centered exhibitions and edu-curation in art museums. Lanham, Maryland: Rowman $\& \&$ Littlefield.

\section{NotA BIOGRÁFICA}

Pedro Andrade é sociólogo, investigador no Centro de Estudos de Comunicação e Sociedade da Universidade do Minho. Doutoramento em Sociologia da Cultura na FCSH, Nova Universidade de Lisboa (2002). Autor de livros e artigos sobre museus de arte e ciência, comunicação e literacias, redes sociais digitais (Web 2.0/Web 3.0), metodologias e hipermédia. Coordenador de vários projetos e equipas de investigação, entre eles, Literacia Científico-Tecnológica e Opinião Pública: o caso dos Museus de Ciência; Comunicação Pública da Arte: o caso dos Museus de Arte Locais/Globais, ambos financiados pela Fundação para a Ciência e Tecnologia.

Email: pjoandrade@gmail.com

Morada: Rua D. Luís de Noronha, 26 10D, Lisboa 1050-072, Portugal

* Submetido: 28-02-2018

* Aceite: 15-06-2018 